\title{
Current status of biogas development in Anhui province, China
}

\author{
Li Hui ${ }^{1, a}$, Li Buqing ${ }^{1, b}$, Liu Zuojun ${ }^{1, c}$ \\ ${ }^{1}$ Agricultural Engineering Research Institute, Anhui Academy of Agricultural Sciences, Hefei \\ 230031, Anhui, China \\ aleehui8@mail.ustc.edu.cn, ${ }^{b} 13966718237 @ 163 . c o m,{ }^{c} 45399300 @ q q . c o m$
}

Keywords: Biogas, Current status, Future prospect, Anhui province, China

Abstract:Biogas technology, with the health, environment, economy and energy benefit, has attracted significant public and legislative attention for a long time. Despite the multiple benefits of biogas, there are some exist barriers including economic, political and social issues that have become major obstacle to its development. Accordingly, based on the detailed situation of biogas project, this paper presents the development status of biogas project in Anhui province, China. The conclusion is that medium-large/super-large biogas project should be encouraged, promoted and invested, some relevant policies and legislation should also be implemented for the commercialization of biogas in Anhui province.

\section{Introduction}

Anaerobic digestion (AD) is one of the most widely used technologies to reduce environmental pollution and produce biogas renewable energy throughout the world, especially in developing countries. This technology aims to convert organic waste to biogas and fertilizer which is considered to be clean and environmentally friendly. The number of biogas project in China has been increasing in recent years with strong support from government, and a series of policies and programs have been formulated to promote the development of biogas ${ }^{[1,2]}$.

Anhui province $\left(114^{\circ} 54^{\prime}-119^{\circ} 37^{\prime} \mathrm{E}, 29^{\circ} 41^{\prime}-34^{\circ} 38^{\prime} \mathrm{N}\right)$ is located in the central China, of which rural population covering $77.07 \%$ of the total in 2011 . This region represents a major agricultural province and a pivotal production area of wheat, rice, and maize $\mathrm{e}^{[3]}$, the average ground temperature is $>20^{\circ} \mathrm{C}$ for only 4-6 months and always exceeds $10^{\circ} \mathrm{C}$ each year ${ }^{[4]}$. In addition, Anhui province is rich in agricultural residues and manure resources ${ }^{[5]}$, which is suitable to develop biogas project. A wealth of literature have been published about the development status, opportunities, constraints of biogas in China, while most of the researches are focused on the whole country ${ }^{[6]}$. In fact, Anhui province is a typical agricultural province, its biogas development process will provide a strong demonstration effect for other area.

This paper focuses on the present situation and challenge of biogas project. Biogas development in Anhui province was selected as a case study to evaluate the developmental trend of biogas. In addition, problems and recommendations of biogas upgraded are put forward, with the hope of improving and promoting the policy change to accelerate the development of biogas technology in China.

\section{Historical development}

China, as one of the earliest biogas consumers in the world, has paid great attention to the biogas industry. The construction of biogas began in the late 1850s, among which the first simple ferment biogas was invented in Gunagdong province. And then, more and more digesters (such as hydraulic pressure digester, floating cover digester, semi-plastic-type digester, and tank digester) with the volume of $6-10 \mathrm{~m}^{3}$ were established ${ }^{[7,8]}$, which had been popularized throughout China. With decade years of research and practical application, the number of rural household biogas ranks first in world. By 2007, 26.5 million biogas plants with the output reachs 10.5 billion $\mathrm{m}^{3}$ had been built ${ }^{[9]}$. However, due to the rapid process of urbanization and industrialization, the huge transformation of the mode of production and way of living has occured in rural area, thus most of the household biogas digesters are 
not operating well ${ }^{[10]}$. Based on the statistics data, more than $36 \%$ of household biogas projects were discontinued in Guizhou, and the data for Shannxi was nearly $70 \%{ }^{[11]}$. The primary reason for this was attributed to technical level, financial support and social factors ${ }^{[12]}$.

Up to 2010, a large number of the medium-large biogas project had been constructed, with the number increased nearly 30 times compared to it in the year 2001. These project were mainly focused on large livestock and poultry farms, from which the biogas can be used for cooking and heating for farm region and also as a supplement for local villagers and factories. Meanwhile, new policies and increased subsidies had been implemented by the Chinese government. Surveys indicated that the medium-large biogas projects produced higher energy efficiency and better social effect, as well as reduced the environmental problems caused by poultry breeding ${ }^{[13,14]}$. There are still some bottleneck problems, such as daily management, biogas transport, secondary pollution, and so on, which will restrict its development ${ }^{[15]}$. In 2015, about 2 billion RMB Yuan has been invested to support super-large scale biogas plants, with the total volume of each digesters is more than $5000 \mathrm{~m}^{3}$, biogas will be purified as vehicles fuel, with similar characteristics of natural gas. Super large biogas project has higher energy efficiency and better social effect based on the study of Song et al ${ }^{[13]}$. This technology has just begun in China, while is widely used in Europe ${ }^{[16]}$.

\section{Current status of biogas project in Anhui province}

\section{Project overview}

As a typical agricultural province in China, Anhui province has a unique advantage in agricultural production, with a high output of major agricultural products, and also be one of the 12 major cotton producing area. Fig. 2 shows the number of medium-large biogas project in Anhui province, from 2005 to 2015 , the number of the new project was steadily increasing, with the highest value in 2010. More than 200 biogas projects have been invested in Anhui province, with total installed digester volume of 0.13 billion $\mathrm{m}^{3}$, and nearly 23.33 billion $\mathrm{m}^{3}$ biogas is produced per year. In 2015, a super-large scale biogas plant with a volume of $20000 \mathrm{~m}^{3}$ was approved, of which the biogas would be purified for vehicle fuel.

As for household biogas project, from 2007 to 2014, more than 6 million rural household biogas had been invested in Anhui province, ranking first in China. However, most of the biogas projects are poorly runing, underutilized, or even deserted ${ }^{[17]}$. The main reason for this situation includes several following aspects, the reduction of rural labor, popularization of commercial fuel, as well as the decline in backyard farming ${ }^{[15]}$. As a consequence, Anhui government has shown more increasing preference for large and super large biogas project over rural household biogas, thus Anhui people's livelihood projects had decided to no longer support the rural household biogas project (volume less than $500 \mathrm{~m}^{3}$ ) since 2015.

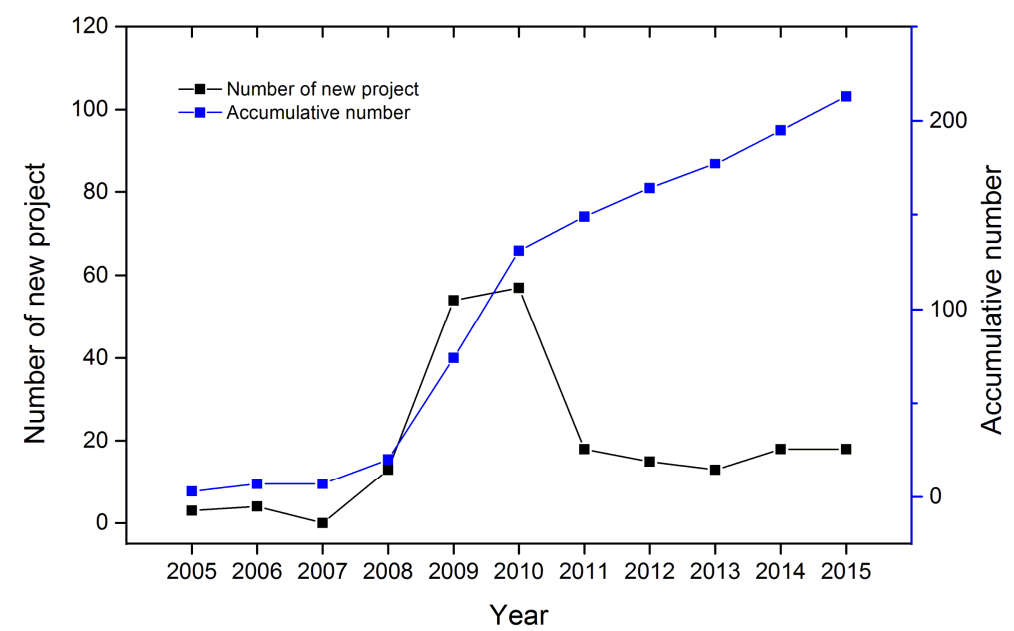

Fig. 1. Number of medium-large biogas project in Anhui province, China 


\section{Operation information}

Over $98 \%$ projects are located in large livestock farms that rely on animal manure, which is an ecosystem of transforming waste to energy. Among the established biogas projects, up-flow solid reactor (USR) and continuously stirred tank reactor (CSTR) are two most common technology, since these techniques are more mature and suitable for manure digestion in Anhui province. Generating electricity is the primary use of biogas, accounting for more than $80 \%$. Biogas slurry and residue are mainly used as foliar fertilizer for vegetables and basal fertilizer for soil, respectivily. Moreover, some biogas residue is processed into organic fertilizer for merchandise.

According to the study of Li and Zhang ${ }^{[18]}$, less than $80 \%$ of biogas projects in Anhui province are operational. Some of them are unreasonable designed and constructed, as well as incorrect operation. Except for the project itself, the poor responsibility of users and instability of poultry industry is the main reason for this. In addition, the most important reason is government's failure to monitor and provide technology support for the biogas project.

\section{Barriers against biogas development in Anhui province}

\section{Institutional barriers}

More than $80 \%$ biogas was used for electricity generation in Anhui province, with the value of 14.43 million kwh per year, but this number accounts for a very small percentage compared to coal power plant, also its poor stability makes it hard to connect to the power grid. How to coordinate the relation between power company and biogas project will be a big problem.

\section{Economic barriers}

From 2005 to the end of 2015, the government had invested millions RMB Yuan to support the development of biogas, and 23.33 billion $\mathrm{m}^{3}$ biogas is produced per year. Essentially, every household is more inclined to use this energy, because of the lower price than liquefied petroleum gas and more environmental friendly than firewood. But until now, no commercial biogas trading company has been built in Anhui province, almost financial support of construction and operation are derived from the government, even though the biogas has high economic value. Thus, promoting the commercialization of biogas from self-reliant biogas project will be a main task for the government.

\section{Technological barriers}

To ensure a sufficient source supply for biogas project, crop straws have attached extensive attention in Anhui province. It can not only recycle agricultural residues, but also reduce greenhouse gas emission. However, due to the high content of cellulose, hemicellulose and lignin, straws show poor degradability and low efficiency in the process of anaerobic digestion. Different pretreatment methods (physical, chemical, physico-chemical and biological methods) had been used for the straws

${ }^{[19]}$, but these methods are hard for wide practical application due to high cost and difficult to handle. In addition, large scale livestock farm biogas project have huge amount of biogas slurry and residue which will lead to secondary pollution if lack of appropriate treatment ${ }^{[20]}$, thus how to reduce residue and increase the production of biogas is also a shortage of technology.

Remote monitoring system is also necessary to gather detailed information about each biogas project $^{[21]}$, in this system, operational parameters can be detected in time, as well as send remote instruction. This system can ensure the biogas project safety and transmit the data to the manager.

\section{Conclusions}

Biogas project has achieved rapid development under the strong support by the government in Anhui province, however some negative obstacles also existed.

1. Presently, medium-large and super-large are two main types biogas project that supported by government.

2. The appropriately funded research regarding biogas technology is essential to reduce biogas residue and improve the digestion rate, and some new technology should also be well adopted. 
3. Economics, technology, legislation and personal motivation are all essential for the commercialization of biogas.

\section{Acknowledgements}

This work was financially supported by the President Youth Innovation Fund of Anhui Academy of Agricultural Science (NO.16B1326), Sub-project of National Science and Technology Supporting Program (NO.2015BAL01B01-05), Subject Construction Project of Anhui Academy of Agricultural Science (NO.15B1324) and Anhui Sci-tech Plan Project (NO.1501031116).

\section{References}

[1] X. Jiang, S. G. Sommer, and K. V. Christensen, A review of the biogas industry in China, Energy Policy, vol. 39, no. 10, pp. 6073-6081, (2011)

[2] Y. Feng, Y. Guo, G. Yang, X. Qin, and Z. Song, Household biogas development in rural China: On policy support and other macro sustainable conditions, Renewable and Sustainable Energy Reviews, vol. 16, no. 8, pp. 5617-5624, (2012)

[3] H. Wu, Z. Yuan, Y. Zhang, L. Gao, and S. Liu, Life-cycle phosphorus use efficiency of the farming system in Anhui Province, Central China, Resources, Conservation and Recycling, vol. 83, pp. 1-14, 2, (2014)

[4] S. Piao, P. Ciais, Y. Huang, Z. Shen, S. Peng, J. Li, L. Zhou, H. Liu, Y. Ma, and Y. Ding, The impacts of climate change on water resources and agriculture in China, Nature, vol. 467, no. 7311, pp. 43-51, (2010)

[5] Y. Chen, W. Hu, and S. Sweeney, Resource availability for household biogas production in rural China, Renewable and Sustainable Energy Reviews, vol. 25, pp. 655-659, 9//, (2013)

[6] W. Ding, H. Niu, J. Chen, J. Du, and Y. Wu, Influence of household biogas digester use on household energy consumption in a semi-arid rural region of northwest China, Applied Energy, vol. 97, pp. 16-23, (2012)

[7] Y.-c. GAO, Z.-s. KUANG, M.-s. PAN, X.-g. HUANG, W. CHEN, M.-q. YE, Z.-h. XU, M.-w. ZHANG, and G.-s. XIAO, Development progress and current situation analysis of the rural household biogas in China Guangdong Agricultural Sciences, vol. 11, pp. 22-27, (2006)

[8] X. Zeng, Y. Ma, and L. Ma, Utilization of straw in biomass energy in China, Renewable and Sustainable Energy Reviews, vol. 11, no. 5, pp. 976-987, (2007)

[9] Y. Chen, G. Yang, S. Sweeney, and Y. Feng, Household biogas use in rural China: a study of opportunities and constraints, Renewable and sustainable energy reviews, vol. 14, no. 1, pp. 545-549, (2010)

[10] W. Zhang, F. Yin, N. Liu, S. Liu, H. Gong, J. Li, H. Guan, J. Li, Y. Xiao, and Y. Mao, Industrial development and marketable analysis on rural biogas, Trans CSAE, vol. 22, no. Suppl 1, pp. 72-6, (2006)

[11] X. Wang, X. Lu, G. Yang, Y. Feng, G. Ren, and X. Han, Development process and probable future transformations of rural biogas in China, Renewable and Sustainable Energy Reviews, vol. 55, pp. 703-712, (2016)

[12] J. Han, A. P. Mol, Y. Lu, and L. Zhang, Small-scale bioenergy projects in rural China: Lessons to be learnt, Energy policy, vol. 36, no. 6, pp. 2154-2162, (2008)

[13] Z. Song, C. Zhang, G. Yang, Y. Feng, G. Ren, and X. Han, Comparison of biogas development from households and medium and large-scale biogas plants in rural China, Renewable and Sustainable Energy Reviews, vol. 33, pp. 204-213, (2014)

[14] G. Wang, W. Liu, X. Wang, D.-y. GAO, D.-x. HE, and W. CHEN, Current status and prospect of biogas technology in China, Applied Energy Technology, vol. 12, pp. 33-35, (2007)

[15] L. Chen, L. Zhao, C. Ren, and F. Wang, The progress and prospects of rural biogas production in China, Energy Policy, vol. 51, pp. 58-63, (2012) 
[16] B. YIN, L.-m. CHEN, and Q.-p. KONG, Research on purification technology for vehicle biogas [J], Modern Chemical Industry, vol. 11, pp. 009, (2009)

[17] P. WEI, X.-j. WANG, R. WU, F. WANG, and Y.-h. LI, Construction situation and development strategies of rural biogas in middle-west China [J], Guangdong Agricultural Sciences, vol. 2, pp. 088, (2010)

[18] L. quanlin, and X. Zhang, Development Situation and Prospect of Large and Medium-sized Biogas Project in Anhui Province, China biogas, vol. 1, no. 32, pp. 84-89, (2013)

[19] Y. Zheng, J. Zhao, F. Xu, and Y. Li, Pretreatment of lignocellulosic biomass for enhanced biogas production, Progress in Energy and Combustion Science, vol. 42, pp. 35-53, 6//, (2014)

[20] M. Syed, G. Soreanu, P. Falletta, and M. Béland, Removal of hydrogen sulfide from gas streams using biological processes-a review, Canadian Biosystems Engineering, vol. 48, pp. 2, (2006)

[21] T. Radu, R. E. Blanchard, A. D. Wheatley, and J. Taylor, Real-time autonomous remote monitoring of $\mathrm{AD},(2015)$ 